\title{
Capsule Commentary for McGinty et al., Effects of Maryland's Affordable Care Act Medicaid Health Home Waiver on Quality of Cardiovascular Care Among People with Serious Mental Illness
}

Tracey L. Henry, MD, MPH, MS and Erica Heiman, MD, MS

Division of General Medicine and Geriatrics, Emory University School of Medicine, Atlanta, GA, USA.

$J$ Gen Intern Med 35(11):3421

DOI: $10.1007 / \mathrm{s} 11606-020-06154-\mathrm{w}$

(c) Society of General Internal Medicine 2020

I $\mathrm{n}$ this study, Dr. McGinty and her co-authors examine the receipt of recommended cardiovascular care by recipients of Mayryland's Behavioral Health Home (BHH) program in comparison with Medicaid enrollees not enrolled in the program. ${ }^{1}$ The authors examine this cohort of patients with diabetes and/or cardiovascular disease via retrospective chart analyses, with outcome measures that include provision of statins, measurement of laboratory markers of diabetes and cardiovascular disease, and clinical evaluations of diabetic complications. Interestingly, this study mostly reports negative results; the only outcome with an increased likelihood among the BHH participants was receipt of a diabetic eye exam.

Studies like this are key to mitigating the disparities in health care for those who are living with serious mental illness (SMI). The need for care coordination is clear, as some patients with SMI can become so decompensated that they never make it to the rehabilitation center for care of chronic medical conditions. ${ }^{2}$ This study is a much-needed look at cardiovascular care provision within an integrated care model. Of the two previous studies with similar objectives and outcomes, one-whose findings did support improved care measures for BHH recipients-was a clinical trial, which represents a structured environment that may not be replicated when the model is implemented in a real-world climate. ${ }^{3,4}$ The other, an observational cohort of a BHH program in New York state, also found no effect of receipt of these services on hemoglobin A1c monitoring. ${ }^{5}$

Taken together, these studies question the value of $\mathrm{BHH}$ programs towards improved cardiovascular disease care. Although this study's methods present some limitations - chart abstraction alone may misrepresent reality if documentation is not accurate, and pharmacy fill data may not represent what a patient actually takes - there is a suggestion that BHH programs may not be effectively integrating primary care with behavioral health services, exposing patients to higher risks of disease complications. What is needed is better understanding of how integrated care models can more effectively reduce disparities, and clarification of which components of integrated care systems are most critical in achieving improved outcomes for patients with SMI.

Corresponding Author: Tracey L. Henry, MD, MPH, MS; Division of General Medicine and Geriatrics, Emory University School of Medicine, Atlanta, GA, USA (e-mail: henrytracey@hotmail.com).

\section{Compliance with Ethical Standards:}

Conflict of Interest: The authors declare that they do not have a conflict of interest.

\section{REFERENCES}

1. McGinty E, Stone EM, Kennedy-Hendricks A, Bandara S, Murphy KA, Stuart EA, Rosenblum MA, Daumit GL. Effects of Maryland's Affordable Care Act Medicaid Health Home Waiver on Quality of Cardiovascular Care among People with Serious Mental Illness J Gen Intern Med. https://doi. org/10.1007/s11606-020-05690-9

2. Bao Y, Casalino LP, Pincus HA. Behavioral health and health care reform models: patient centered medical home, health home, and accountable care organization. J Behav Heal Serv Res 2013;40:121-132.

3. Druss BG, von Esenwein SA, Glick GE, et al. Randomized Trial of an Integrated Behavioral Health Home: The Health Outcomes Management and Evaluation (HOME) Study. Am J Psychiatry. 2017;174(3):246-255.

4. Yawn BP, Dietrich A, Graham D, et al. Preventing the voltage drop: keeping practice-based research network (PBRN) practices engaged in studies. J Am Board Fam Med 2014;27(1):123-135.

5. Breslau J, Leckman-Westin E, Yu H, et al. Impact of a mental health based primary care program on quality of physical health care. Adm Policy Ment Health Ment Health Serv Res 2018;45(2):276-285.

Publisher's Note: Springer Nature remains neutral with regard to jurisdictional claims in published maps and institutional affiliations. 